\title{
DE L'ART ANALÒGIC A L'ART DIGITAL: NOUS CONTEXTOS I NOVES PROPOSTES DE RECERCA
}

Malgrat l'art digital és una realitat des de la dècada de 1960, la facilitat de reproduir aquestes obres feia gairebé impossible afirmar l'originalitat i el valor del mitjà. Fa ben poc podíem llegir en diferents diaris que el criptoart entrava al món de la cultura amb gran aldarull després que Christie's vengués Everydays: The First 5000 Days, una obra digitalitzada de Mike Winkelmann -més conegut com Beeple-, per poc més de 69 milions de dòlars. L'obra, un collage realitzat amb 5000 imatges durant més de tretze anys, ha convertit Winkelmann en un dels tres artistes vius més cotitzats del món, juntament amb Jeff Koons i David Hockney. Aquest fenomen mostra una vegada més I'actual tendència disruptiva del mercat de I'art. Els actius digitals NFT (sigles de Non Fungible Tokens; un NFT representa una obra d'art única) asseguren I'autenticitat i la titularitat d'una obra sense marge d'error, garanteixen que no es tracta d'una còpia i funcionen com a unitats de valor digitals que permeten $d^{\prime}$ interactuar en les xarxes a partir $d^{\prime} u n s$ codis i actuen alhora com un contenidor que transforma una obra d'art digital en un objecte virtual que es pot recopilar. Això permet, d'una banda, l'evolució del col·leccionisme d'art en si mateix, perquè ara l'art digital pot posseir les mateixes qualitats que donen valor a una obra d'art física -escassetat i singularitat- i, d'una altra i al mateix temps, manté la seva qualitat única d'accessibilitat visual infinita en el seu format natiu. Els NFT no reemplaçaran les obres d'art tradicionals però faran possible un mercat entorn d'una nova generació d'artistes que funcioni com a catalitzador de l'art digital vinculat a la xarxa monetària Ethereum. Aquest nou sistema permet fer tota mena $d^{\prime}$ 'intercanvis i d'inversions en fotos, il·lustracions, podcasts, notícies, reportatges, vídeos, memes, gifs, etc. Ha vingut el criptoart per a quedar-s'hi o no és més que una simple moda? Quin valor tenen les obres d'art envers el nou context que afavoreix Internet? Davant aquesta realitat tan complexa, tot es relativitza. 
En el camp de la creativitat actual en general i de la creativitat artística en particular, els valors de corporeïtat, temporalitat i tangibilitat han originat noves maneres de creació que requereixen una nova manera d'investigar el fenomen artístic. Ja no cal que les obres siguin materials ni que perdurin en el temps: el virtual i l'efímer regnen en aquest nou món. Els processos de creació digitals i la circulació de I'obra seran dos dels objectius que hauran d'imposar-se els agosarats historiadors de l'art que afrontin aquest nou repte. Els blockchain -una estructura de dades la informació de les quals s'organitza en cadenes de blocs connectats amb metadades i que, entre d'altres aplicacions, ha permès el desenvolupament de les xarxes monetàries de criptodivises- seran els equivalents als arxius i documents que fins ara ens han permès avançar en les recerques acadèmiques, ja que facilitaran informació sobre I'obra i el seu recorregut. Els propietaris de les obres artístiques no seran particulars anònims ni museus, sinó una Ilarga cadena de propietaris que tindran potencialment una obra que serà alhora en milions de llocs per al seu gaudi i fruïció. L'experiència estètica estarà condicionada per la distància entre l'objecte virtual i el subjecte digital (creador i espectador) i tindrà un caràcter potencial, en el sentit aristotèlic.

És indiscutible que estem davant un canvi de paradigma respecte a la concepció del que és art i de tot el que aquest comporta. No estem parlant de la possessió de béns materials sinó de béns digitals. Això ens porta a reflexionar de nou sobre les principals preguntes que es van plantejar en la postmodernitat, com ara la qüestió de I'autoria i la possibilitat o la impossibilitat d'aportar-hi quelcom de nou, quelcom que no s'hagi fet encara. L'apropiacionisme artístic va apostar per la fragmentació i el collage, entre d'altres procediments, amb la finalitat de recuperar el passat o determinades obres d'art i rellegir-los a partir de la seva inserció en un nou context que podia ser crític sobre les derives del món. Assistim ara a un nou apropiacionisme que transforma obres analògiques en obres digitals. El fet que es converteixin en objectes ubics, distribuïts, en possibilita nous mercats, noves formes de comercialització i nous canals, més adaptats a aquests nous suports. La revolució de Gutenberg sembla repetir-se en els nostres dies. La democratització de I'art reviu un nou episodi en la història de la creativitat. L'elitisme del qual presumien els grups socials més acomodats en posseir una obra material es posa en dubte, ja que altera per complet les nocions de propietat i de propietari.

La difusió i el consum de continguts creatius estan revolucionant radicalment el mercat de l'art. Les obres creades amb NFT i blockchain poden convertir-se en diners de manera immediata gràcies a les denominades $f i$ nances descentralitzades ( $\mathrm{DeFi}$ ), en total sintonia amb les noves eines de pagament i d'identificació i amb els contractes intel·ligents. L'absència d'in- 
termediaris permet d'arribar a un públic més ampli, plantejar-ne una promoció més global i afavorir un nou model de col·leccionisme i mecenatge.

$\mathrm{Hi}$ ha un exemple artístic que em sembla interessant portar a col·lació: el de I'artista Refik Anadol, el treball del qual, basat en la intel·ligència artificial (IA), es pot trobar a Nifty Gateway. Anadol, davant la incomprensió i el desinterès de les galeries i els centres d'art tradicionals, ha optat per donar-se a conèixer mitjançant aquest nou sistema digital. Gràcies a la tecnologia blockchain, pot seguir el rastre de les seves obres i saber en tot moment on són i qui les posseeix.

Els artistes digitals poden comercialitzar les seves obres, establir-ne el valor i vendre-les a col-leccionistes que ara tenen un registre de propietat. El valor de I'obra està en relació amb la quantitat de persones interessades en la mateixa i en el preu de sortida que l'artista determini.

No hi ha dubte que, en un futur més o menys pròxim, la recerca en el camp artístic continuarà fent-se d'acord amb uns mètodes i pràctiques ja tradicionals. No obstant això, haurà d'acceptar aquesta nova realitat que ens brinda l'entorn digital. Els processos, les metodologies i els resultats passaran per tots els canvis que implica el digital, ja sigui la realitat augmentada i la cocreació, en estimular-se la interdisciplinarietat, la multidisciplinarietat i la transdisciplinarietat. Però tot això que relatem en aquestes pàgines encara està per començar i el que encara ara tenim són les recerques en història de I'art d'encuny acadèmic basades en I'analògic, com les que presentem en aquest número miscel·lani que alberga a autors i temàtiques molt interessants d'èpoques molt diferents, amb angles i perspectives de recerca molt heterogenis.

L'article «Els ulls del Vescomte. Mirades, mutacions i trasbalsos del sepulcre gòtic de Ramon Folc de Cardona, el Prohom Vinculador, a Poblet», de Pere Beseran, se centra en la recent restauració del sepulcre de Ramon Folc VI de Cardona i en la seva reubicació dins de I'església del monestir de Poblet i planteja la hipòtesi sobre el caràcter factici de l'actual estructura i sobre la damnatio memoriae infligida al rostre i els ulls del jacent, a partir de la llegenda sobre la lluita del vescomte amb les ratapinyades diabòliques que el van encegar, en un interessant cas de relectura de les representacions medievals després d'haver estat manipulades.

Els «Dos manuscritos en busca de autor: Pedro de Toledo, copista e iluminador en Sevilla», de Jorge Jiménez López, tracta I'agrupació que va realitzar I'arquebisbe Diego de Anaya (1357-1437) d'una de les col·leccions de Ilibres més notables de la Castella tardomedieval. Els dos manuscrits seleccionats ( $B G H, M s .2638$ i Ms. 1906) permeten d'aprofundir en els encàrrecs de la seva etapa final, al capdavant de la diòcesi sevillana tenint-ne en compte el testament en favor de Pere de Toledo i la proximitat 
dels repertoris amb els seus treballs que perfilen la personalitat artística del controvertit personatge.

La recerca de Lucía Lahoz Gutiérrez porta per títol «Apostillas a un debate historiográfico. La capilla de San Jerónimo del Estudio de Salamanca» i aborda la Capella de l'Estudi de Salamanca. Es determina la seva localització original en la capella que componia un àmbit religiós, civil i representatiu, imprescindible per al funcionament institucional. El recinte acollia tant les reunions del claustre com la celebració de les festes previstes en el calendari escolar. La construcció d'una biblioteca en la part superior va implicar una complexa obra de renovació per a la qual es va encarregar un retaule a Felipe Bigarni i Juan de Flandes, i que va concloure amb la unificació de tots dos espais. L'autora, a més, qüestiona I'autoria del Cielo de Salamanca, tradicionalment atribuït a Fernando Gallego, i proposa una lectura iconològica d'aquesta «arquitectura d'autor».

«Les col-leccions bibliogràfiques d'Alexandre de Riquer a la Biblioteca Joaquim Folch i Torres del Museu Nacional d'Art de Catalunya», de Yolanda Ruiz Ruiz, centra la seva atenció a la biblioteca privada del seu antic propietari, com també en la seva col·lecció d'enquadernacions artístiques i en un exemplar incunable del Breviarium cartusianum. Gràcies a Alexandre de Riquer, la Biblioteca Joaquim Folch i Torres del Museu Nacional $d^{\prime}$ Art de Catalunya conserva un interessant fons bibliogràfic patrimonial.

"Traditional Japanese pottery and its influence on the American mid $20^{\text {th }}$ century ceramic art», de Johannis Tsoumas, té com a objectiu abordar la influència significativa que I'art ceràmic estatunidenc de postguerra va rebre dels ideals tradicionals de la ceràmica japonesa. L'autor, amb la finalitat de documentar les raons d'aquest nou ordre de coses, estudia i analitza l'obra d'importants ceramistes estatunidencs de l'època, i destaca el context social, filosòfic i cultural de l'època en què es desenvolupa tota I’obstinació.

Pablo Sánchez Izquierdo, en «Tan nuestro, tan de nuestra tierra. La consagración del paisajismo en Alicante a través de la literatura de Gabriel Miró y la pintura de Emilio Varela», estableix interessants relacions entre les novel-les de I'escriptor i els olis de I'artista plàstic, i hi descriu la seva recepció a la ciutat a tenor de l'interès que va mostrar la crítica i de les exposicions que es van celebrar a partir de llavors.

Pel que respecta al cinema, I'article "La representación de los niños en los largometrajes de ficción de Flora Gomes: diálogo entre el arte africano y el cine», de Bàrbara Beatriz Laffita Menocal, mostra els punts de convergència i divergència entre la representació dels nens en l'art africà i en la producció cinematogràfica de ficció del realitzador Flora Gomes, natural de Guinea Bissau. Primerament, i de manera molt resumida, hi exposa 
aquelles tipologies plàstiques en les quals apareix el nen i, a continuació, hi identifica els contextos en els quals es tracten aquestes temàtiques i hi analitza la manera en què s'aborden en els films.

Finalment, Guadalupe Estel, en «Saraceno y la araña: la figuración posthumana, entre reapropiaciones y derivas no antrópicas», realitza una lectura crítica de I'obra recent de I'artista argentí Tomás Saraceno des de la perspectiva del materialisme posthumà per a assenyalar com es reprodueix en aquest exemple una lògica que fa de tot I'existent una pedrera disponible per a l'extracció de recursos teleològicament destinats a l'existent humà. L'autora encunya el terme figuració posthumana per a pensar alternatives no antròpiques que habilitin maneres de ser imaginaris més enllà de tota prerrogativa humana.

Dra. Magda Polo Pujadas

Codirectora de Matèria. Revista Internacional d'Art

Universitat de Barcelona magda.polo@ub.edu 
Aquest article ha estat publicat originalment a Matèria. Revista internacional d'Art (ISSN en línia: 2385-3387)

Este artículo ha sido publicado originalmente en Matèria. Revista internacional d'Art (ISSN en línea: 2385-3387)

This article was originally published in Matèria. Revista internacional d'Art (Online IS S N : 2385-3387)

\section{MATÈRIA}

Revista internacional d'Art

Els autors conserven els drets d'autoria i atorguen a la revista el dret de primera publicació de l'obra.

Els textos es difondran amb la llicència de Reconeixement-NoComercialSenseObraDerivada de Creative Commons, la qual permet compartir I'obra amb tercers, sempre que en reconeguin I'autoria, la publicació inicial en aquesta revista i les condicions de la llicència: https://creativecommons. org/licenses/by-nc-nd/4.0/deed.ca

Los autores conservan los derechos de autoría y otorgan a la revista el derecho de primera publicación de la obra.

Los textos se difundirán con la licencia de Atribución-NoComercial-SinDerivadas de Creative Commons que permite compartir la obra con terceros, siempre que éstos reconozcan su autoría, su publicación inicial en esta revista y las condiciones de la licencia: https://creativecommons.org/licenses/ by-nc-nd/4.0/deed.es

The authors retain copyright and grant the journal the right of first publication.

The texts will be published under a Creative Commons Attribution-NonCommercial-NoDerivatives License that allows others to share the work, provided they include an acknowledgement of the work's authorship, its initial publication in this journal and the terms of the license: https://creativecommons.org/licenses/by-nc-nd/4.0/deed.en

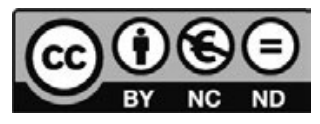

